\title{
Investigation of the Effects of Sports Education on University Students' Stress Coping Strategies
}

\author{
Erol Dogan
}

Ondokuz Mayis University, Faculty of Sports Science, Samsun, Turkey.

Email:_erol._ogan@omu.edu.tr Tel:+905305228266

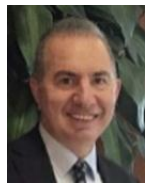

\begin{abstract}
The aim of this study is to investigate the effect of sports education on university students' strategies to cope with stress. 150 sports sciences and 150 education faculty students participated in the study. "Ways of Coping Inventory" scale was used as data collection tool in the study. Mann Whitney $U$ test was performed in statistical processes. In terms of the faculty variable, the scores of the sports science faculty students who received Social Sports education in the subdimension of "self-confident approach" and "optimistic approach" were found higher than the students who did not receive sports education $(p<0.05)$.In addition, it was determined that the students of the education faculty who did not receive sports education had high scores from the sports science students who received sports education under the sub-dimension of "self-confident approach" and "social support seeking approach" ( $\mathrm{p}<0.05)$. According to gender, it was determined that the scores that men got from the Self-Confident and Optimistic approach subdimensions were statistically higher than those of women $(p<0.01)$. Result: It is concluded that sports education at university level has a positive effect on students' strategies to cope with stress. It can be said that taking sports education is effective in increasing self-confident and optimistic approach and accordingly developing self-confidence. It is recommended that feelings of selfconfidence of faculty students who do not have sports education should be raised by giving courses and seminars on sports.
\end{abstract}

Keywords: University student, Sports education, Stress, Success, Social Sports, Positive effect.

Citation | Erol Dogan (2020). Investigation of the Effects of Sports Education on University Students' Stress Coping Strategies. Asian Journal of Education and Training, 6(3): 474-478.

History:

Received: 27 April 2020

Revised: 7 June 2020

Accepted: 3 July 2020

Published: 15 July 2020

Licensed: This work is licensed under a Creative Commons

Attribution 3.0 License (c) E E

Publisher: Asian Online Journal Publishing Group
Funding: This study received no specific financial support.

Competing Interests: The author declares that there are no conflicts of interests regarding the publication of this paper.

Transparency: The author confirms that the manuscript is an honest, accurate, and transparent account of the study was reported; that no vital features of the study have been omitted; and that any discrepancies from the study as planned have been explained.

Ethical: This study follows all ethical practices during writing

\section{Contents}

1. Introduction

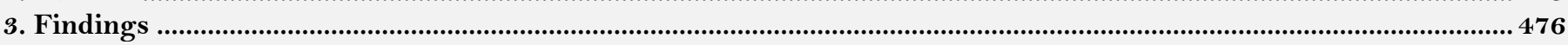

4. Discussion

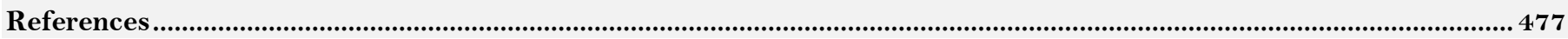




\section{Contribution of this paper to the literature}

With the end of their education life, students may encounter a situation where they can be uncertain for their future. This can affect students' stress and anxiety levels. Therefore, this study was conducted to investigate the effects of sports education on university students' strategies to cope with stress. The emergence of a positive impact on university students' strategies to cope with stress by sports education can lead students who do not receive sports education to do sports.

\section{Introduction}

Sport is defined as a competitive solidarity, and cultural phenomenon that develops the capabilities acquired while transforming the natural environment of the individual into the human environment, with or without tools under certain rules, integrates with the socializing society that he / she does by personally or collectively within the scope of his leisure activity or by taking his full time (Erdal, 1982; Inal, 2003). Considering the increasing importance of the sport due to its diversity and functions, the science of psychology has been used to increase efficiency, and through the emerging Sport Psychology, all positive or negative psychological processes that may affect the performance of the athlete have been approached. Although the harmful effects of stress are well known, stress levels are high in the general population (Klaperski, Von Dawans, Heinrichs, \& Ve Fuchs, 2014).

Current stimuli are defined as a process that turns stress into objective perceptions based on cognitive evaluations of individuals, regardless of whether they are actually stressors / stressful factors. In this sense, when individuals consider stimuli from the outside world as compelling for themselves, they attempt to cope with them. These attempts include cognitive or behavioral efforts to reduce or control the effect of the internal and external compulsion of the stimuli faced by the individual (Erdal, Arslan, Saygın, \& Ozyeşil, 2009). The positive effect of sports in reducing stress level has been revealed in researches (Imamoğlu, Tutkun, \& Sen, 2018). According to some sources, the effort that the individual spends beyond her physical and psychological limits due to the negative conditions coming from the physical and social environment is called stress (Cuceloğlu, 1996). The stress that everybody talks about today is a fact of life. Researches show that everyone's definition of stress is according to him (Deniz \& Yimaz, 2006; Sahin, 1998). Individuals face many economic and environmental stress situations caused by the family in their daily lives. Individuals experience many economic, family-related and environmental stress situations in their daily lives. University students also have issues to deal with, such as adaptation issues, housing, academic issues, and friendship relationships. Students can take steps towards the solution of these problems or choose the way to escape from these problems (Deniz \& Yimaz, 2006). Stress, unrealistic and high levels of expectations of families and coaches in the environment of young athletes cause athletes' stress to rise to high levels. In addition, the fact that young people are below the level of sports they do and their high levels of performance impairment are causing problems for young athletes to understand and cope with internal stress (Akandere, 2003; Turkay \& Sökmen, 2014). Today, people are under constant pressure and stress. Especially young people's need to be more active, innovation and change causes various troubles and problems (Uzun, Imamoğlu, Yamaner, Deryahanoğlu, \& Yamaner, 2017).

Stress damages the physical energies of the athletes, their gains and victories, their pleasure and fun. Stress can harm athletes' self-confidence by making them think they are not skilled. Psychological stress can hurt athletes to demonstrate the skills they have achieved by working for years and prevent athletes from having flow experience. Stress can lead to injury to athletes and lead them to early retirement. Stress is a latent and insidious disease. This may reflect itself in overtraining (mental, emotional, social and physical burnout) (Altungül \& Devecioğlu, 2006; Turkay \& Sökmen, 2014). Coping with stress is "the conscious effort of the individual to manage the intensity and demands of the event that is perceived as stressful. It is also the development of the individual's resources, self-control and self-confidence to manage and reduce the perceived stress intensity" (Lazarus, 1999). Time management is often a recommended method to deal with stress. If the person manages his work time well, he can save himself from daily pressures. Generally, aerobic exercises are more effective in decreasing the stress level (Akyol \& Imamoğlu, 2018). In the last years, a lot of research has been done to control and manage the feeling of people (Goodman, Kashdan, \& İmamoğlu, 2020). In a study by Yamaner, Cplak, and Imamoğlu (2020) found sports education has a positive effect on university students' optimal performance. With the end of their education life, students may encounter a situation where they can be uncertain for their future. This can affect students' stress and anxiety levels. Therefore, this study was conducted to investigate the effects of sports education on university students' strategies to cope with stress.

\section{Method}

\subsection{Participants}

300 students participated in the study, including 150 Education Faculty (age; $22.02 \pm 1.64$ years) and 150 Yaşar Doğu Sports Sciences Faculty (22.47 \pm 1.56 years) students studying at Ondokuz Mayıs University.

\subsection{Data Collection Tools}

Descriptive Characteristics Form: The descriptive property form is composed of questions about gender, age and type of education in all the participants.

Stress Coping Strategies Scale (SCSS): Adaptation study of the scale used in this study and originally developed by Folkman and Lazarus with the original name of "Ways of Coping Inventory "to Turkish society was made by Sahin and Durak. The scores of Likert type "SCSS" are obtained between 0-3 ( $0=0 \%, 1=30 \%, 2=70 \%$, and $3=100 \%$ ) and separate scores are obtained from the subscales. In scoring the scale, items 1 and 9 are scored reversely. Şahin and Durak determined that five factors were formed in the reliability studies of the scale of "PBL" and that the Cronbach Alpha coefficients of these factors ranged between 0.47 and 0.80 . The researchers determined that the scale's validity and reliability were sufficient and it could be used to measure strategies to cope with stress as a result of studies in which the relations of the scale were determined with psychological symptoms, various personality dimensions, situational variables and contrast group comparisons were made. In our study, the 
Cronbach Alpha coefficient was found to be 0.73. Scale Factors and explanations about the factors are as follows (Sahin \& Durak, 1995):

1. Self-Confident Approach (SCA): To evaluate the importance of the problem and solution options, to be cautious and planned in the solution, to make active, logical and conscious efforts to change the situation $(8,10,14$, $16,20,23$, and 26 ).

2. Lack of Self Confidence Approach (LOSCA): In the face of events or problems, most of the energy is not to solve the problem, but to blame himself, find himself weak, and direct himself to see himself as the source of the problem $(3,7,11,19,22,25,27$, and 28$)$.

3. Optimistic Approach (OA): It is a more tolerant and optimistic approach to events and a more calm and realistic assessment of problems $(2,4,6,12,18)$.

4. Submissive / Helpless Approach (S/HA): It means feeling helpless with a fatalistic approach and looking for a solution in supernatural forces $(5,13,15,17,21$, and 24$)$.

5. Social Support Seeking Approach (SSSA): Sharing their problems with someone else is expressed as seeking help from others for solution $(1,9,29$, and 30$)$.

\subsection{Statistical Analysis}

The statistical analysis of the data obtained in the research was made using the SPSS 23.00 package program. The Kolmogorov Smirnov test was used to check whether the data showed normal distribution. Comparison between the two groups was made by Mann Whitney U since it was determined that the data did not show normal distribution.

\section{Findings}

The ages of the students participated in this study were determined as 22.47 years for the faculty of sports sciences and 22.02 years for the students of the Faculty of Education.

Table-1. Comparison of SCSS sub-dimension scores by faculties (sports education n=150, education faculty (non-sports education) $\mathrm{n}=150$ ).

\begin{tabular}{|c|c|c|c|c|c|c|c|}
\hline Parameter & Status & Mean & Std D. & Median & $\min$ & $\max$ & $\bar{Z}$ \\
\hline \multirow[t]{2}{*}{$\begin{array}{l}\text { Self-Confident } \\
\text { (SCA) }\end{array}$} & Non-sports education & 13.89 & 3.53 & 14 & 5 & 21 & \multirow[t]{2}{*}{$-2,107^{*}$} \\
\hline & Sports Education & 14,69 & 3,61 & 15 & 6 & 21 & \\
\hline \multirow{2}{*}{$\begin{array}{l}\text { Lack of Self Confidence } \\
\text { Approach (LOSCA) }\end{array}$} & Non-sports education & 10,71 & 4,31 & 10 & 1 & 22 & \multirow[b]{2}{*}{$-3,971^{* *}$} \\
\hline & Sports Education & 8,62 & 4,20 & 9 & $\mathrm{O}$ & 20 & \\
\hline \multirow[t]{2}{*}{ Optimistic Approach (OA) } & Non-sports education & 8,69 & 2,74 & 9 & 2 & 15 & \multirow[b]{2}{*}{$-2,016^{*}$} \\
\hline & Sports Education & 9,26 & 2,54 & 9 & 1 & 15 & \\
\hline \multirow{2}{*}{$\begin{array}{ll}\text { Submissive } \quad / & \text { Helpless } \\
\text { Approach (S/HA): } & \end{array}$} & Non-sports education & 6,15 & 3,04 & 6 & $\mathrm{O}$ & 15 & \multirow[b]{2}{*}{$-0,627$} \\
\hline & Sports Education & 6,39 & 2,96 & 6 & $\mathrm{O}$ & 14 & \\
\hline \multirow{2}{*}{$\begin{array}{lll}\text { Social } & \text { Support } & \text { Seeking } \\
\text { Approach } & \text { (SSSA) } & \end{array}$} & Non-sports education & 7,75 & 2,18 & 8 & $\mathrm{O}$ & 12 & \multirow[b]{2}{*}{$-2,423^{*}$} \\
\hline & Sports Education & 7,17 & 2,00 & 7 & O & 11 & \\
\hline
\end{tabular}

Note: *p<0.05 and $\mathrm{p}<0.001$

In Table 1, the differences obtained from the sub-dimensions of the SCSS scale are given in terms of the faculty variable. In terms of the faculty variable, significant differences were found in the sub-dimensions of the scale's SelfConfident and Lack of Self-Confidence Approaches, Optimistic Approach and Social Support Seeking Approach (p $<0.001)$.

Table-2. Comparison of SCSS sub-dimension scores by gender.

\begin{tabular}{|c|c|c|c|c|c|c|c|c|}
\hline Parameter & Gender & $\mathrm{n}$ & Mean & Std D. & Med. & Min. & Max. & $\mathbf{Z}$ \\
\hline \multirow{2}{*}{ Self-Confident Approach (SCA) } & Male & 121 & 15,29 & 3,55 & 15 & 6 & 21 & \multirow[b]{2}{*}{$-3,993^{*} *$} \\
\hline & Female & 179 & 13,61 & 3,46 & 14 & 5 & 21 & \\
\hline \multirow{2}{*}{$\begin{array}{llll}\text { Lack of Self Confidence } & \text { Approach } \\
(\text { LOSCA }) & & \end{array}$} & Male & 121 & 8,50 & 4,21 & 9 & $\mathrm{O}$ & 20 & \multirow[b]{2}{*}{$-3,504^{* *} *$} \\
\hline & Female & 179 & 10,42 & 4,32 & 10 & 1 & 22 & \\
\hline \multirow[t]{2}{*}{ Optimistic Approach (OA) } & Male & 121 & 9,53 & 2,66 & 10 & 1 & 15 & \multirow[t]{2}{*}{$-3,269^{* *}$} \\
\hline & Female & 179 & 8,60 & 2,59 & 9 & 2 & 15 & \\
\hline \multirow[t]{2}{*}{ Submissive / Helpless Approach (S/HA): } & Male & 121 & 6,41 & 3,05 & 6 & $\mathrm{O}$ & 14 & \multirow{2}{*}{$-0,701$} \\
\hline & Female & 179 & 6,18 & 2,97 & 6 & $\mathrm{O}$ & 15 & \\
\hline \multirow[t]{2}{*}{ Social Support Seeking Approach (SSSA) } & Male & 121 & 7,09 & 2,14 & 7 & O & 11 & \multirow{2}{*}{$-2,374^{*}$} \\
\hline & Female & 179 & 7,70 & 2,05 & 8 & 1 & 12 & \\
\hline
\end{tabular}

Note: ${ }^{*} \mathrm{p}<0.05$ and $\mathrm{p}<0.001$.

In Table 2, the differences obtained from the subscales of the SCSS scale are given in terms of gender variable. It was determined that the scores of men in the SCA and OA sub-dimensions were statistically higher than women $(p<0.01)$. When the LOSCA scores were analyzed, it was seen that women had higher scores than men $(p<0.01)$. When the SSSA sub-dimension was examined, it was found that women had higher scores than men $(p<0.05)$. 


\section{Discussion}

In our study, the scores obtained from the sub-dimensions of the SCSS scale were examined according to the faculty variable in which the education was conducted. In the four sub-dimensions of the scale, significant differences were found between the students of the sports science faculty (SSF) who received sports education and the students of the Faculty of Education (EF) who did not receive sports education. It has been determined that the students who are studying in the SSF have higher scores from the SCA sub-dimension and the OA sub-dimension than the students who are studying in EF. It was determined that the scores of students studying in EF from the LOSCA subscale were statistically significantly higher than SSF students $(p<0.01)$. When SSSA subscale scores were compared between two faculties, EF students had higher scores than SSF students $(p<0.05)$. It can be thought that there may be a growing awareness depending on the sports science students doing sports. In addition, athletes' generating strategies to win during the match may likewise affect the occurrence of difference. Ciçek, Imamoğlu, Yamaner, and Türk (2017) stated that 3-month exercise decreases depression level in women. Turkay and Sökmen (2014) stated in the study where they investigated students' level of coping with stress that the scores of athletes in the School of Physical Education and Sports were higher than the middle level. This situation, which occurs in athletes, is explained by the ability to actively fight stress sources. In another study, it was stated that the satisfaction of people with their external appearance may cause them to think positively (Yamak, Imamoğlu, Islamoğlu, \& Cebi, 2018). It is claimed that people who do sports are much more friendly, extroverted, enough to work harder, more patient, better in establishing social relations, better adapting to a new position and more psychologically balanced personality than non-sports individuals (Yamak \& Imamoğlu, 2019). The outlook of the students who have received sports training is probably better than those who have not received sports training. In another study, it was accepted that the students who do sports have good leadership qualities (Cetinkaya \& İmamoğlu, 2018). In this study, it was determined that the students who are studying in EF have higher scores from the LOSCA sub-dimension than SSF students. It is understood that EF students are more inclined not to solve the problem in the face of events or problems, but to blame themselves, find themselves weak, and see themselves as the source of the problem than SSF students. With the end of the education life, in this process that will start business life, it is thought that graduation fields of people will affect their employment. It can be said that the situations related to job opportunities of the education faculty students make up this difference. From this result, it is understood that SSF students evaluate the importance and solution options of more problems and are more cautious and planned in the solution and they make active, logical and conscious efforts to change the situation compared to EF students. In addition, the fact that SSF students get higher scores in OA dimension compared to EF students shows that SSF students are more tolerant and optimistic about the events and evaluate the problems more calmly and realistically.

Arslan, Gullu, and Tual (2011) stated that they did not find a significant difference between depression scores of female students who do sports and female students who do not do sports. However, they stated that female students who do not do sports have higher depression scores. Sports education can make positive changes in personality traits (Koca, Imamoğlu, \& Imamoğlu, 2018). It has also been reported that stress levels decrease in individuals who do sports (Deryahanoğlu, İmamoğlu, Yamaner, \& Uzun, 2016). Exercise has been found to improve the quality of life of university students (Imamoğlu., 2020). People develop feelings and attitudes about their bodies according to the ideal measures offered to them. Failure to take the desired measures may cause negativity in the self-assessment of individuals (Yamak, Imamoğlu, \& Cebi, 2016). In this study, when SSSA subscale scores were compared between two faculties, it was seen that EF students had higher scores than SSF students. This result shows that students studying at EF share their problems with someone else more than SSF students and they want more help from others for solution. Yamaç (2009) stated that the social support levels that female students receive from family, friends and private individuals are significantly higher than male students. It can be said that this difference may affect the difference between genders. Durna (2006) and Uluruh (2008) stated that there is no definitive finding that girls and boys show completely different styles of coping with stress. In this study, it was determined that men's SCA and OA scores were higher than women by gender. From this finding, it is understood that men make more active and conscious efforts to evaluate the importance of the problem and solution options and to change the situation compared to women, the fact that men's OA scores are higher than women shows that men evaluate events more tolerantly, calmly and realistically than women. Again in this study, it was determined that women had higher LOSCA score than men. This result can be interpreted as that women blame themselves more for problems than men and use their energy less in solving the problem. Again, the fact that women had higher SSSA scores than men; brings to mind that women share their problems with someone else and ask for help.

It is concluded that sports education at university level has a positive effect on students' strategies to cope with stress. It can be said that taking sports education is effective in increasing self-confidence and optimistic approach and accordingly developing self-reliance. It is concluded that self-confidence and lack of self-confidence, optimistic approach and social support seeking approach change among university seniors among men and women by gender. It is recommended that faculty students who do not have sports education should be raised their feelings of selfconfidence by giving courses and seminars on sports.

\section{References}

Akandere, M. (2003). Investigation of depression levels of students doing sports and non-sports. Journal of Sports and Medicine, Syndrome, $4(2), 1-3$.

Akyol, P., \& Imamoğlu, O. (2018). The effect of Aerobic step exercise on stress level, life quality and menstrual status in women. Turkish Studies, $13(27), 87-96$.

Altungül, O., \& Devecioğlu, S. (2006). Determination of the stress level of individuals who get involved in football activities in the light of their personality traits. International Journal of Sport Studies, 5(1), 7-11.

Arslan, C., Gullu, M., \& Tual, V. (2011). Examining the depression states of primary and elementary school students according to some variables. Journal of Physical Education and Sports Sciences, 5(2), 120-132.

Cetinkaya, G., \& İmamoğlu, G. (2018). Research on leadership tendency of students taking sports education according difference variations. The Journal of International Social Research, 11(59), 719-725. 
Ciçek, G., Imamoğlu, O., Yamaner, F., \& Türk, N. (2017). Psychological effects of cardio bosu exercise on sedentary women. International Journal of Sports, Exercise and Training Science, 3(3), 69-75.

Cuceloğlu, D. (1996). Man and his behavior. Istanbul: Remzi Bookstore.

Deniz, M., \& Yimaz, E. (2006). Examining the relationship between emotional intelligence and stress coping styles of university students. Turkish Psychological Counseling and Guidance Journal, 3(25), 17-26.

Deryahanoğlu, G., İmamoğlu, O., Yamaner, F., \& Uzun, M. (2016). Anthropometric characteristics of sedentary women and comparison of their psychological states comparison of anthropometric features and psychological states of sedentary women. Journal of Human Sciences, 13(3), 5257-5268.Available at: https://doi.org/10.14687/jhs.v 13i3.4106.

Durna, U. (2006). Investigation of University students 'stress levels In terms of some variables. Atatürk University Journal of Economics and Administrative Sciences, 20(1), 319-343.

Erdal, M. (1982). Sport in sociological perspective (pp. 7). Istanbul: Filiz Kitap Evi.

Erdal, H., Arslan, C., Saygın, Y., \& Ozyeşil, Z. (2009). Analysis of university students' approaches to coping with stress in terms of selfesteem and irrational beliefs. Journal of Values Education, 7(18), 25-42.

Goodman, F., Kashdan, T., \& İmamoğlu, A. (2020). Goodman, F. R., Kashdan, T. B., \& İmamoğlu, A. (2020). Valuing emotional control in social anxiety disorder: A multimethod study of emotion beliefs and emotion regulation. Emotion. Advance online publication.Available at: http://dx.doi.org/10.1037/emo0000750.

Imamoğlu, O., Tutkun, E., \& Sen, G. (2018). Stress level and self relation in University students and coaches. Acta Scientiae et Intellectus, 4(1), 25-30.

Imamoğlu, O. (2020). Investigation of quality of life according to the exercise behaviour change stages of women studying at University. European Journal of Physical Education and Sport Science, 6(3), 47-59.

Inal, A. (2003). Physical education and sports science (pp. 7). Ankara: Nobel Yayın Dağıtım.

Klaperski, S., Von Dawans, B., Heinrichs, M., \& Ve Fuchs, R. (2014). Effects of a 12-week endurance training program on the physiological response to psychosocial stress in men: A randomized controlled trial. Journal of Behavioral Medicine, 37(6), 1118-1133.

Koca, F., Imamoğlu, G., \& Imamoğlu, O. (2018). Sports status of high school students and investigation of personality characteristics by gender. The Journal of Academic Social Science, 6(80), 31-42.

Lazarus, R. S. (1999). Stress and emotion: A new synthesis. New York: Springer Publishing CompanyInc.

Sahin, N. H. (1998). A positive approach to coping with stress. Ankara: Turkish Psychological Association Publications.

Sahin, N., \& Durak, A. (1995). Adaptation of stress coping scale for University students. Turkish Journal of Psychology, 10(34), 56-73.

Turkay, H., \& Sökmen, T. (2014). Physical education and sports department students' sources of motivation in sports and styles of coping with stress. Inonu University Journal of Physical Education and Sports Sciences, 1(3), 1-9.

Uluruh, A. (2008). Administrator behaviors that cause stress in secondary school students and coping behaviors in students. Unpublished Master Thesis. Dokuz Eylul University, Institute of Educational Sciences, Izmir.

Uzun, M., Imamoğlu, O., Yamaner, F., Deryahanoğlu, G., \& Yamaner, G. (2017). Examining the factors that prevent participation in recreational activities: Girl high school example. Journal of Human Sciences, 14(1), 950-962.

Yamaç, O. (2009). The relationship between social support perceived by University students and their styles of coping with stress. Doctoral dissertation, Selcuk University Institute of Social Sciences.

Yamak, B., Imamoğlu, O., Islamoğlu, İ., \& Cebi, M. (2018). The effects of exercise on body posture. Turkish Studies Social Sciences, 13(18), 1377-1388.

Yamak, B., Imamoğlu, O., \& Cebi, M. (2016). The effects of the physical fitness levels of adolescents on body image, self-concept and stress levels. The Journal of Academic Social Science, 4(34), 191-201.

Yamak, B., \& Imamoğlu, O. (2019). The beck hopelessness level according to behavior change stages in University Ondokuz Mayis Students. Turkish Studies Educational Sciences, 14(3), 937-947.

Yamaner, F., Cplak, E., \& Imamoğlu, O. (2020). Investigation of optimal performance emotional status in sports students. Turkish Studies, $15(2), 1515-1522$. 